\title{
Nietzsche después de Schopenhauer
}

\author{
SOSSIO GIAMETTA \\ Bruselas, CEE
}

\section{Maestro y Discípulo}

Entre los grandes pensadores, Nietzsche es quizás el que más ha tomado de otros. Entre sus 'precursores' se pueden contar al menos los catorce autores que señala su biógrafo Charles Andler. Sin embargo él ha reconocido como «único maestro y severo educador» al «gran» Arthur Schopenhauer ${ }^{1}$. Él es el más grande seguidor de Schopenhauer, aunque sea con signo opuerto, hasta el punto de que se exclarecen muchas cosas de su maestro estudiando la relación que tuvo su discípulo rebelde con su filosofía: una luz de contraste, que es importante para la intepretación del maestro así como para la interpretación del discípulo. Es necesario al respecto destruir la leyenda que el mismo Nietzsche ha querido crear sobre el desacuerdo que él hubiese tenido desde le primer momento con la filosofía de Schopenahuer. Nietzsche dice que admiró en Schopenhauer al filósofo de cuño antiguo, que hace de la filosofía su vida, pero que no fue conquistado por su filosofía. ${ }^{2}$ Sin embargo, es verdad que en los fragmentos póstumos de 1867-1869 o sea, dos y cuatro años después de la primera lectura de Schopenhauer, manifiesta su desacuerdo sobre varios puntos de la filosofía schopenahueriana; pero también es verdad que El nacimeinto de la tragedia, de 1871, es una obra netamente schopenhaueriana, por su planteamiento metafísico y el evidente destello en ella de la temática schopenahueriana. En esta obra Nietzsche «une los antiguos símbolos: Dioniso, Apolo y Sócrates, directamente con Schopenhauer y Wagner, interpretándolos con la óptica, la metafísica de la

${ }^{1} \mathrm{SE} \$ 1$.

${ }^{2}$ «Mi desconfianza hacia el sistema desde el comienzo. En primer plano venía la persona, él típico como filósofo y promotor de la cultura [...] para mí el único efecto era la generación del filósofo - pero yo mismo fui impedido por la superstición del genio. Cerrrar los ojos» KGW IV 30[9], verano de 1878. 
filosofía schopenhaueriana», como afirma Curt Paul Janz. ${ }^{3}$ El cual añade que en El nacimiento de la tragedia. "Nietzsche busca, partiendo de la metafísica schopenhaueriana, una posición contrapuesta y sustitutiva del crisitanismo [...] y la reencuentra en el símbolo de Dioniso-Zagreo, en el mito de Dioniso descuartizado, de la desmembración del Uno originario en los distintos individuos, en el mundo de las apariencias, que él designa como la parte 'apolínea'. El Uno originario [...] - la 'voluntad' de Schopenhauer - es para él inmediatamente experimentable y viene efectivamente experimentado a través de la música» ${ }^{4}$. Erwin Rohde reconoce por su parte en El nacimiento de la tragedia, "por lo que respecta a la explicación y justificación del fenómeno, una significación análoga a la que posee la propia obra fundamental de Schopenhauer en lo referente a la indagación de la esencia de las cosas que se agita debajo de todos los fenómenos» ${ }^{5}$. Como dice Thomas Mann, la obra de Nietzsche constituye entonces «una continuación y transformación» de la de Schopenhauer.

Es verdad que con el tiempo Nietzsche se distanció cada vez más de Schopenhauer, hasta mantener con él una polémica cada vez más insistente, ya sea mediada por expresiones reiterativas de respeto, que terminaron finalmente en el escarnio. Pero durantae un largo tiempo vivió admirando al maestro, haciendo proselitismo y erigiendo todavía, a los nueve años de la lectura de El mundo, aquel monumento a Schopenhauer que es la tercera consideración intempestiva: un monumento no sólo a la vida, sino también a la ética de Schopenhauer, en el fondo la parte más discutible del sistema. Ésta contiene entre otras cosas una exaltación del genio, considerado siempre por Nietzsche sentido y fin de la existencia de los hombres, que está en sorprendente contraste con sus afirmaciones contrarias, contenidas en el fragmento 30[9]11 del verano de $1878^{6}$. Si finalmente se considera que en el aforismo 99 de La gaya ciencia todavía se exaltan, aunque junto a un elenco de defectos, cuatro teorías 'inmortales' de Schopenhauer: la intelectualidad de la intuición, la prioridad de ley de la casualidad, la instrumentalidad del intelcto y la no liberad de la voluntad, el pretendido repudio inmediato de la filosofía schopenhaueriana no consigue credibilidad y se revela como una reflexión a posteriori, finalizada con la reivindicación de una independencia

${ }^{3}$ Janz, C. P., Friedrich Nietzsche. 2. Los diez años de Basilea, Madrid: Alianza, 1978, p. 131. ${ }^{4}$ Ibid., pp. 134 y 405.

${ }^{5}$ Janz, C. P., op. cit., vol. I, p. 432. En al raducción hemos sutituido 'que se hace sentir' (sich regenden) por 'que se agita'. Para Schopenhauer la voluntad no duerme nunca y por lo tanto no está nunca ni siquiera 'despierta'.

${ }^{6}$ Ver nota 2. 
incautamente alienada. Esta alienación, sin embargo, había sido fruto de una veneración subjetiviamnte generosa y deisnteresada, pero objetivamente había sido la mejor inversión de Nietzsche, porque había sido importantísima para su formación.

\section{EL QUIASMA}

Todos saben y dicen que «Nietzsche procede de Schopenhauer y contrapone a su pesimismo la afirmación trágica». Sin embargo, hasta ahora nadie ha tratado de resolver este lugar común con una reflexión rigurosa. Pero si esto no ha sucedido, es porque las respuestas de Nietzsche a las cuestiones de Schopenhauer no son simétricas, sino sesgadas, ya que forman con aquella un quiasma. Dicho incidentalmente, ésta es tambien la dificultad de situar a Nietzsche en la historia de la filosofía. Esto no quiere decir que entre las dos posiciones falte completamente la simetría: eso es lo que hace decir a algunos, como por ejemplo a Giorgio Colli, que el pensamiento de Nietzsche no es más que el pensamiento de Schopenhauer invertido. La simetría está particularmente en la elección y en el planteamiento de los temas, y no en la contraposición a la negación de Schopenhauer, o sea al egoísmo que está en la base del pesimismo schopenhaueriano, de la abnegación, es decir, de un desinterés heróico y de un amor leal a la vida, que comportan, con la máxima fruición, la máxima abnegación de hecho. Pero, por otra parte, Nietzsche ha contrapuesto a la parte derivada, la parte que se manifiesta y en alguna manera temperamental, de la filosofia de Schopenhauer, su pesimismo 'romántico', debido según él a la temprna edad (26 años) en que su sistema fue concebido ${ }^{7}$, la parte fundamental, positiva del propio pensamiento: la visión dionisiaca; mientras que a la parte fundamental de la doctrina de Schopenahuer ha opuesto a su instalación conceptual y a su metafísica, la parte derivada instrumental de la propia doctrina, es decir, un escepticismo renovado, poetizado y potenciado respecto a aquel inaugurado por Kant.

En cuanto al pesimismo de Schopenhauer no se puede evitar el ponerlo en relación con el optimismo de Hegel: el último intento filosófico grandioso de divinizar el mundo. Mientras que Hegel enseñaba un un aula repleta en la Universidad de Berlín, la cabalgada triunfal a través dela historia de su Weltgeist o Espíritu del mundo, en otra aula casi vacía Schopenhauer negaba toda esperanza de salvación fundada sobre la historia. En cuanto al escepticismo de Nietzsche, éste es de naturaleza neo-sofística, pero muchos,

${ }^{7}$ KGW VII 25[11] primavera 1884. 
sobre la base de una orientación provisional, lo confunden con el iluminismo. Mientras que esa, sin embargo, que en lo profundo es crítica histórica, crítica de la civilización, encaja superficialmente con la función investigadora del iluminismo, no encaja de hecho con la función social y progresista que, junto con la primera, constituye la característica esencial del iluminismo. En realidad, el escepticismo de Nietzsche es la otra cara de la reivindicación de independencia del hombre y la inversión necesaria de la visión dionísiaca, su arma defensiva y ofensiva, con la que se combate aquello que es el enemigo natural de tal visión poética, abierta: la filosofía sistemática, cerrada. Y es por este caracter suyo derivado, funcional y reactivo, falto de unidad y autonomía, por lo que el pensamiento escéptico de Nietzsche está obligado a expresarse por medio de aforismos y sentencias, y no puede llegar a ser sistema. De aquí la ansiedad de toda una vida para el autor, que solo al final abandonó su sueńo de un proyecto sistemático. No se dió cuenta de que tenía ya su 'sistema', su unidad y autonomía, en su moralismo poético, ya que su escepticismo, que servía a tal moralismo, no podía ser más que crítico con algo, cosas y filosofemas que fuesen, y que por consiguiente le hacía falta algo para criticarlo, que era simpre diverso y que se podía encontrar sólo en el cauce del gran río histórico.

\section{No FILÓSOFO SINO MORALISTA}

¿Por qué Nietzsche luchaba contra la filosofía sistemática? Por una razón que puede parecer hasta demasiado simple: porque tenía alma de poeta y los poetas no creen en la filosofía. Pero en esto no se conocía lo suficiente. Se arrepintió de no haber escrito en versos El nacimiento de la tragedia ${ }^{8}$, que Cósima Wagner dijo que había leído como un poema y que Benedetto Croce remitía a la poesía de Fausto; en Zaratustra proclama que «solo en la danza sabe decir el símbolo de las cosas supremas»; y al final se reconoció nur Narr, nur Dichter, solo juglar, solo poeta, no Freier der Wahrheit, no predendiente de la verdad, no filósofo. Pero antes pensaba que la filosofía había sido su verdadera voación. Y se ocupaba de la filosofía sistemática, no del moralismo aplicado a la filosofía, que era su Fach y que él mismo ha distinguido de la filosofía, más aún, lo ha contrapuesto a ella, en la parte inicial del aforismo 5

${ }^{8}$ «Ese 'alma nueva' habría debido cantar - ¡y no hablar! Qué lástima que lo que tenía

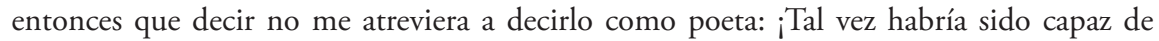
hacerlo!» NT, «Ensayo de autocrítica», \$3, ed. A. Sánchez Pascual, Madrid: Alianza, 1984, p. 29 [citamos las traducciones de Nietzsche por las ediciones de Andrés Sánchez Pascual de Alianza Editorial]. 
de Opiniones y sentencias diversas: «Un pecado original de los filósofos. - En todo tiempo los filósofos se han apropiado de los dichos de aquellos que estudian a los hombres (los moralistaas) y los han corrompido, - precisamente cuando creían elevarse por encima de los moralistas - tomándolos en un sentido absoluto y queriendo demostrar la necesidad de lo que los moralistas habían entendido sólo como indicación aproximativa o incluso solamente como la verdad de una década, propia de un país o de una ciudad [...]».

A continuación del aforismo impugna este error a Schopenhauer, a próposito del cual dice después en el aforismo 33 de la misma obra: «Querer ser justo y querer ser juez. Schopenhauer, cuyo gran conocimeinto del ser humano demasiado humano, cuyo sentido instintivo de los hechos han sido trabados por la piel del leoprado de su metafísica (que hay que quitar antes, para descubriri bajo ella un verdadero genio moralista) [...]»

En el aforismo 214 de El caminante y su sombra, Nietzsche subraya además la superior sustancialidad de los moralistas franceses frente a los filósofos abstractos alemanes, y en el aforismo 254 de Más allá del bien y del mal indica en la "antigua, multiforme cultura moralista», la segunda cosa - después de la capacidad de tener pasiones artísticas y de entregarse a la forma - sobre la que Francia pudo fundar su superioridad cultural repecto al resto de Europa. Por consiguiente tenía bien presente la diferencia entre filosofía y moralismo. Y sin embargo, no la aplicó a sí mimso, violó el patere legen quam ipse tulisti. Trató de conseguir una cátedra de filosofía que quedaba vacante en Basilea, y en la solicitud se decía que estaba «inclinado fortísimamente por naturaleza a meditar filosóficamente en algo unitario, a permanecer prolongada y tranquilamente en un problema haciendo largos razonamientos»" es decir, como lo hacen los filósofos sistemáticos. Durante toda su vida ambicionó escribir 'una obra capital'. Pero nunca la escribió. Y cuando finalmente pensó hacerlo, organizando un cierto número de fragmentos bajo el título de $\mathrm{La}$ voluntad de poder, terminó por no hacer nada, haciendo otra cosa.

Como pensador moralista, poéticamente inspirado, estaba dotado no sólo de talento e ingenio, sino también de genio. Como filósofo puro, por el contrario, le faltaba aquella iniciativa y aquella inventiva en el campo conceptual que convierten al filósofo en original y autónomo: originalidad y autonomía que, por el contrario, Schopenhauer tenía, junto al genio moralista. Las pruebas filosofícas que Nietzsche fue constreñido a hacer - porque ocupándose de filosofía se sentía obligado a llenar los vacíos que él mismo producía con su escepticismo disolvente - fueron al mismo tiempo

${ }^{9}$ C.P. Janz, op. cit., p. 106. 
fallos y degeneraron en mitos malos: el superhombre, el eterno retorno, la inocencia del devenir, la gran esperanza, la gran política, la gran salud, la vountad de poder y, en sus últimos y nefastos resutlados, también la trasvaloración, nacida como instrumento genial de desenmascaramiento. Todas estas fueron reflexiones con resonancia y características, pero pobres, fueron descarrilamientos inducidos por la cultura de la época (evolucionismo) y por la crisis histórica.

Por lo demás, ¿cómo podía ser un verdadero filósofo quien, como él, desvalorizaba la lógica y el concepto, que son el principio y el fin de la filosofía? Si las críticas y las argumentaciones deben estar fundadas sobre algo, Nietzsche, como todos los moralistas, fundaba las suya, en difinitiva, sobre los principios morales y no sobre conceptos. Sin embargo, sobre principios morales no se funda un sistema. Por eso, la comparación que Heidegger hace con Aristóteles (el pensamiento de Nietzschee no sería «menos objetivo y riguroso que el pensamiento de Aristóteles») es lo menos ajustado que se podría encontrar. Nietzsche es más bien un nuevo Gorgias, y ha hecho lo que hizo tambien él: un antisistema, aunque el de Nietzsche, a diferencia del de Gogias, proporcione en definitiva una visión poética, por un lado y obedezca, por otro, a instancias históricas (autodesructivas). En este sentido él pudo llamarse filósofo, como lo hizo el mismo Gorgias, con tal de que se aclare qué se entiende por ese nombre. Nietzsche se lanzaba contra la lógica, porque pensaba que era una máquina autoafirmativa, la cual hace penasble el mundo que no lo es e introduce en el universo caótico los principios internos de orden y racionalidad del hombre, es decir, los principios antropomórficos que tienen como fin la autoconservación.

\section{Pesimismo y optimismo: juicios partidistas.}

El pesimismo de Schopenhauer es algo más que gratuito. Más bien está firmemente enraizado en su aparato conceptual y corresponde a la naturaleza modal, particular, fenoménica de los individuos; y además a la estructura piramidal de los seres vivientes, en la que los que están arriba se nutren de los que están abajo, salvo raras excepciones. A peasr de eso, el noble escritor y poeta Adalbert von Chamisso, en cuya vida y obra la soledad, precariedad y angustia constituyen ingredientes esenciales, aconsejaba a Schopenhauer que no pintase al diablo demasiado negro, porque hubiese sido suficiente con un buen gris oscuro. Es un hecho que, tal y como se ha concebido, es decir, según un criterio abstracto, exclusivo, absoluto y sin compensaciones, el pesimismo 
de Schopenhauer no está justificado. Más aún, es de tal manera unilaeral e inflado, que lo ridiculiza Francesco De Sanctis en el conocido diálogo sobre Schopenahuer y Leopardi, alabadísimo por el mismo Schopenhauer como compedio precioso y completo de su filosofía, a pesar de los puyazos y golpes irónicos a su tendencia. Peor aún. Su desarrollo sistemático concluye con una imposible negación de la voluntad, que es ella misma voluntad -imposible desde el momento en que hasta la ascesis sirve en definitiva a la voluntad, como Nietzsche ha mostrado ${ }^{10}$ - desestabiliza e invierte el sistema en una constante contradicción como Nietzsche mismo no ha dejado de revela ${ }^{11}$. Desarrollado no sin coherencia por sus seguidores, llega después a lo grotesco y a lo trágico. Von Hartmann recomienda el suicidio universal y Mainlader se suicida él mismo. En realidad el pesimismo de Schopenahuer podría coexistir con su opuesto o arruinarse en sí mismo. En el mundo ilimitado en todos los sentidos, no sólo no hay límite para el pesimismo, sino tampoco para el optimismo, no sólo para el mal, sino tampoco para el bien; sobre todo, sea uno que otro, es decir, ya sea el placer o el dolor que a ellos corresponden, son los medios de los que la naturaleza se sirve para guiar desde el interior a los hombres ${ }^{12}$. Así pues, puesto que los hombres no están más allá de la vida, sino que forman parte de ella, aquellos medios no se prestan para fundamentar un juicio sobre la vida ${ }^{13}$.

Por su parte, la afirmación trágica de Nietzsche persigue los bienes de la vida: belleza, felicidad, armonía, amor, inteligencia, integridad, salud, crecimiento, realización, poder; pero sabe que esos están englobados en el caos invencible de la existencia, en su onda beatificante y sin embargo también destructiva, en el juego sin meta del hacerse y deshacerse de los significados, en la inmanente tranasvaloración que alterna adialécticamente humano y ultra humano, profundidad y superficie, verdad y mentira. Por lo tanto, ella acepta también el desorden, la precariedad, la lucha, la injustifica, la vejación, el dolor, la vejez, la enfermedad y la muerte, en suma, los males que de tales bienes son el inevitable cortejo. Más aún, con un vuelo inaudito, hace de la misma precariedad (en vez de la eternidad) la garantía del valor de la vida.

Así pues, la respuesta al filósofo Schopenhauer fué el juglar y el poeta Nietzsche. Pero en el filósofo había también un moralista-poeta y en el

${ }^{10}$ Cf. GM III $\$ 28$, al final

${ }^{11}$ «La fuerza de la conciencia intelectual que sostiene durante toda la vida la contradicción entre ser y querer y lo constriñe a contrdecirse incluso en sus escritos constantemente y casi en cada punto» FW $\$ 99$.

${ }^{12} \mathrm{Cf} . \mathrm{Za} \mathrm{I}$, «De los despreciadores del cuerpo».

${ }^{13}$ Cf. CI «La moral como contranaturaleza». Cf. también JGB $\$ 225$. 
juglar-poeta también un moralista-filósofo, de ahí la afinidad y el quiasma. Sin embargo, si la parte principal de Nietzsche es el pensamiento poético, o sea la afirmación dionisíaca, y la derivada del escpeticismo: en la historia de la filosofía, que conoce encuentros y desencuentros de filósofo, pero no de filósfos y de poetas, el puesto de Nietzsche es el que le espera por el escepticismo, filosficamente razonado, y no por la visión dionisiaca. Ésta permanece bajo (su sobre) el horisonte filosófico, como había permanecidos bajo (o sbore) el horizonte filológico.

\section{ESCEPTICISMO Y NIHILISMO}

El escepticismo nietzscheano, en cuanto se opone a la metafísica de Schopenahuer, parece a primera vista una vuelta a Kant, al Kant de la Crítica de la razón pura (no ciertamente al de la filosofía práctica). El cierre al noumeno, a la cosa en sí, que la primera Crítica pone de relieve, es el mismo al que, siguiendo a Kant, llega Schopenhauer. Éste, además, lo refuerza, aunque vaya después más allá. Segun él, Kant tiene razón al distinguir del fenómeno la cosa en sí, sólo que luego no le dedica a esta ultima una atención especial, como habría tenido que hacer. Para Kant la cosa en sí deriva automáticamente del hecho de que estando el fenómeno condicionado por el sujeto, siendo él una visión subjetiva de algo objetivo, debería ser entonces éste algo objetivo, en si incognoscible, que es precisamente la cosa en si. Pero a Kant se le hizo observar que esta necesidad deriva de la ley de la causalidad, o sea de una ley del sujeto (del intelecto), por consiguiente es sólo una necesidad subjetiva, no valida más allá del ámbito subjetivo. Pero considerar ya la cosa en si un objeto, encarece Schopenhauer, es un error. El objeto, dice, forma parte del fenomeno, es uno de los dos términos inseparables de la representación, apertura del primer ojo sobre el horizonte del ser. La cosa en si no puede ser, por lo tanto, ni sujeto ni objeto: «Sobre el camino de la representación no se podrá nunca ir más allá de la representación; ella es un todo cerrado y no tiene en sus propios medios ningún hilo que conduzca a la esencia, toto genere distinta de ella, de la cosa en sím ${ }^{14}$. Así pues, desde la representación no se llega ni siquiera a la necesidad de la cosa en sí, y en este sentido Kant se ha equivocado al hacer una hipotesis de ella. Sin embargo, para Schopenhauer nostros tenemos acceso a la cosa en si por via interna, es decir, en la autoconciencia. Esa llega a nosotros como 'voluntad'.

\footnotetext{
${ }^{14}$ Schopenhauer, A., Die Welt als Wille und Vorstellung, Wiesbaden: Brockhaus, 1972, vol. I, p. 596.
} 
Nietzsche no acepta estse acceso a la cosa en sí, ni el concepto de voluntad. Pero no se puede decir que su escepticismo signifique una vuelta a Kant, pues Kant no había llegado a una conclusión escéptica. La había escamotée, penetrando en el terreno de la autonomia de la moral. Para Schopenhauer esto es un gran mérito, porque constituye un paso importante hacia la voluntad. Para Nietzsche, por el contrario, es una recaida en la superstición después de que Kant, con acierto y coraje, la había desbaratado ${ }^{15}$. Por eso se entiende ya que Nietzsche, en cuanto a él, no se había movido de aquella conclusión negativa, sino para llevar el escepticismo a su máximo desarrollo: el nihilismo. Hizo esto en dos tiempos: (1) Refutando la metafísica de Schopenhauer; (2) llevando adelante su ascetismo hasta transformarlo en el nihilismo.

\section{Las Críticas a Schopenhauer}

Nietzsche no cree en el paso que Schopenhauer considera que ha abierto en el velo del fenómeno que Kant ha hecho descendenr sobre toda la conciencia humana. En el fragmento 24[6] del verano de 1877, Nietzsche somete el concepto de voluntad a una crítica radical. Contrariamente a lo que afirma Schopenahuer (el hombre existe por una decisión suya que precede a la existencia), antes de que el hombre sea no existe su voluntad individual, que no se sabe qué será. Después, el hombre no conoce, en la autoconciencia, la voluntad de vivir, sino a lo más la voluntad de permanecer en la vida, en suma, el bien conocido instinto de conservación. Pero verdaderamente ni siquiera esto: son solamente sensaciones de placer o dolor en cualquier órgano, absolutamente insignificantes por lo general. De todos modos, esta búsqueda del placer y la huida del dolor no es un hecho primario y originario, como es la voluntad, según Schopenhauer: presupone la experiencia, y ésta presupone a su vez el intelecto ${ }^{16}$. En el fragmento 38[8] de junio-julio de 1885 Nietzsche afirma que la voluntad no es nada de simple, sino que se

15 «Pienso además en el viejo Kant, quien fue sorprendido por el 'imperativo categórico’ como castigo por haber alcanzado subrepticiamente la 'cosa en sî' - otra cosa muy ridícula - y con aquél en el pensamiento volvió a los viejos errores: 'Dios', 'alma', 'libertad' e 'inmortalidad', como una zorra que tiene la mala ocurrencia de volver a su jaula, cuando habían sido su fuerza y su astucia las que habían roto esta jaula» FW \$335. No es inoportuno hacer notar aquí, como signo de afinidad y de fraternidad incluso en lo negativo, que una observación análoga, solo en apariencia maliciosa, se puede hacer a propósito de la teoría del eterno retorno de Nietzsche. Con ellá él recuperó el ser después de haberlo expulsado de todos los modos en favor del devenir, cuando este último le deviene angustioso e insoportable. El eterno retorno destruye la doctrina fundamental de Nietzsche.

${ }^{16}$ KGW IV 24[6], verano de 1877. 
compone conjuntamente de sentimiento, pensamiento y afecto, de los que no se puede disociar. En el fragmento 10[F 98], de comienzos de 1881, afirma que sin el reconocer ni el deducir no hay voluntad. En el aforismo 5 de Opiniones y sentencias diversas, que después de la parte ya citada es todo un ataque a Schopenhauer, define la vountad como una metáfora poéticca, y en el fragmento 47[5] de septiembre-noviembre de 1879 dice que el gran error de fondo de Schopenhauer ha sido no haber comprendido que 'la apetencia (la 'voluntad') es sólo una especie de conocimiento y nada más'.

En el fragmento Sobre Schopenhauer de 1868 afirma que la voluntad «es una palabra de cuño grosero y muy comprensiva» y dirige a Schopenahuer cuatro críticas: (1) la cosa en sí es sólo una categoría escondida; (2) la voluntad es fruto de una intuición poética; (3) a la cosa en sí, incognoscible e impensable, se le atribuyen predicados sacados del mundo fenoménico, como unidad, atemporalidad y libertad, o sea, falta de fundamento; (4) «la trama esencial de Schopenhauer se le escapa de las manos [...] sobre todo porque el mundo no se deja atrapar tan comodamente en un sistema ${ }^{17}$. Otras críticas están contenidas en el citado aforismo 99 de La gaya ciencia, que es una especie de balance de las virtudes y defectos de Schopenhauer. Particularmente se revelan allí los engorros y subterfugios místicos, se declara indemostrable la teoría de la voluntad, se critican la negación del individuo, la exaltación del genio, la compasión como quiebra del principium individuationis y como fuente de toda moralidad. Al final de este aforismo Nietzsche confirma la propia posición de apertura y de aceptación valiente de la vida trayendo a colación un pasaje de la cuarta intempestiva en la que afirma que «la pasión es mejor que el estoicismo y la hipocresía, que el ser sinceros, incluso en el mal, es mejor que perderse a sí mismo en la moralidad de la tradición, que el hombre libre puede ser tanto bueno como malo, pero que el hombre esclavo es una ignominia para la naturaleza y no participa de ningún consuelo celeste o terrenal».

En cuanto al tránsito del ascetismo al nihilismo, es descrito bien en el aforismo 357 de La gaya ciencia, bien en el parágrafo 28 y último de la tercera disertación de La genealogía de la moral.

\section{El individuo y LA ESPECiE}

Otro motivo de contraste entre Nietzsche y Schopenhauer es su diversa concepción del individuo. Una crítica a la concepción del individuo de

\footnotetext{
${ }^{17}$ Nietzsche, F., Appunti filosofici 1867-1869. Omero e la filologia classica, ed. G. Campioni y F. Gerratana, Milano: Adelphi, 1990, pp. 92 ss.
} 
Schopenhauer se contiene implícitamente en la concepción del individuo de Nietzsche. Para el primero el individuo no cuenta nada: cuenta la especie ${ }^{18}$. Para el segundo cuenta sólo el individuo: El individuo es algo totalmente nuevo e innovador, algo de absoluto, cada acción es suya ${ }^{19}$. Para el hombre, solamente el individuo tiene la máxima importancia; sobre él mide la importancia de los siglos, a él le pone la corona de la inmortalidad, en él ama a la humanidad ${ }^{20}$. La especie es el rebaño, es la alianza de los mediocres para defenderse contra los grandes ${ }^{21}$. En el Zaratustra habla Nietzsche verdaderamente del Selbst como 'el emperador poderoso' que manda desde el interior a los individuos, impponéndoles hacer o no hacer esto o aquello para no sentir dolor o para sentir placer ${ }^{22}$, y no se da cuenta de que este Selbst no es otra cosa que la especie de Schopenhauer. Ambas concepciones son de todos modos parciales, unilaterales, y sin embargo contienen importantes elementos de verdad por los cuales, si están oportunamentae unidos, ponen de relieve una verdad fundamental que ha sido buscada inutilmente durante milenios.

Se puede objetar a Schopenhauer que la especie no existe sino en los individuos, incluso si no se indentifica con ninguno de ellos en particular, pero siempre es sólo con el conjunto de ellos en su número actual. De este número depende de hecho su articulación (en pirámide), y de ésta el emerger en el vértice el 'genio', es decir, aquellos individuos altamentae representativos en los que las necesidades de la especie se encarnan como necesidades personales. Estos individuos viven necesidades objetivamente altruistas, 'genéricas', en forma egoísta ${ }^{23}$. Esto sucede sobre todo en períodos de afirmación colectiva,

${ }^{18}$ «El individuo por el contrario tiene para la naturaleza sólo un valor indirecto, es decir, sólo en cuanto es un medio para conservar la especie», Schopenhauer, A., Die Welt als Wille und Vorstellung, II, p. 401.

${ }^{19}$ Janz, C. P., op.cit., vol. I, p. 13.

${ }^{20}$ Ibid., p. 647.

${ }^{21}$ Cf. FW $\$ \$ 23,116,143,149$.

${ }^{22} \mathrm{Za}$ «De los despreciadores del cuerpo».

${ }^{23}$ Y aquello que Nietzsche entiende cuando habla de 'egoísmo superior' y aquello que Croce habría debido entender cuando decía que el individuo es una institución - él lo entendía del espíritu. La especie es el límite en el que se para cada uno de sus miembros, y la humana es concretamente lo que muchos imaginan como Dios, el espíritu, el absoluto, etc. Más allá de ella el hombre va solo con el pensamiento abstracto, no con el sentimiento. Las razones del corazón que la razón no conoce son las razones de la especie. Otro punto importante es el problema que se plantea por la mezcla, en los grandes hombres, de las razones de la especie con las razones estrechamente individuales, 'privadas', es decir, aquellas superiores con las inferiores. Su portador, que quiere estar a su favor, no puede hacer avanzar las primeras sin hacer avanzar también las segundas, es decir, a menudo el mal con el bien. 
generalmente en los primeros tiempos de una civilización, de un movimiento, de una corriente. De aquí se comprende ya en qué sentido la conecpción de Nietzsche es correcta. Da una máxima relevancia al individuo, porque sólo en la forma del individuo la especie encuentra sus cumplimientos más altos, sus relaciones más plenas. Y ciertamente, para conseguir el indiviudo sus fines (concebido por Nietzsche en general como gran individuo y a su máximo como superhombre), debe vencer las resistencias que le oponen los otros individuos en la lucha de todos contra todos. Pero tal concepción que es luego equivocada degenera, en cuanto interpreta esta división con la finalidad de lucha y de autorrealización como una división instituida, permanente e inmutable que saca al individuo de su matriz natural. Por consiguiente Nietzsche ve el tirunfo de su individuo sobre todo en las épocas de corrupción y de disgregación del tejido conexionado de la sociedad.

Esta concepción aparentemente autónoma, que pone en primer término en definitiva al Gewaltmensch, el individuo desencadenado, que según Nietzshe no debe servir a nadie ni a ninguno salvo a si mismo y a su propia sed de dominio, correspondía en realidad a la actual situación de decadencia de los valores y de degeneración de la civilización. Era la situación que se expreaba teoréticamente a través de Nietzsche, en cuanto la cultura no es 'lujo, calma y voluntad', sino el cumplimiento de los acontecimientos históricos. Los tiempos de la especie son los tiempos de la juventud, de la fuerza y de la moralidad, o sea de la vitrtud y de la grandeza. Los tiempos del individuo son los tiempos de la vejez, del debilitamiento, de la amoralidad (de la naturaleza desnuda y cruda), o sea, de las virtudes y de la grandiosidad ${ }^{24}$. Juntando los elementos válidos de las dos concepciones, se llega a aquello que es el verdadero fundamento de la moral: la encarnación individual de las necesiades de la especie sobre la base de la solidaridad biológica, como fuerza de gravedad interna ${ }^{25}$.

${ }^{24}$ Partiendo de lo que se ha dicho aquí de Nietzsche, no hay que concluir que Schopenahuer, por haber asignado la primacía a la especie, fuese inspirado, por el contrario, por una época de juventud, moralidad, etc. Su apuesta por la especie no es una exaltación de la misma, sino más bien es una connotación negativa que recuerda la fuerza por hacer valer, contra ella, el pesimismo y la negación. Y es a través del pesimimso y de la negación como él manifiesta la pertenencia a su época.

${ }^{25}$ El drama de la moral no es que no haya o no tenga fundamento, sino que el desinterés del individuo sirve al interés de la especie, su utilidad así como la grandeza y el altruismo del político sirven a la utilidad y al egoismo del Estado. Por consiguiente, la moral es una nobleza individual que sirve a una utilidad supraindividual. 


\section{La autodefensa de Schopenhauer}

No es este el lugar para discutir a fondo la fundamentación de las críticas que Nietzsche hace a Schopenahuer. Lo he hecho en otros lugares ${ }^{26}$ y no me arrepiento de haberlo hecho. Citaré sin embargo una parte del fragmento que me parece el más significativo de la autodefensa de Schopenahuer y decisivo, por lo que respecta a nuestro porblema. En el cap. 17 de los Suplementos a El mundo como voluntad y representación, Schopenhauer dice: "Cuando encontramos un escrito cuyo alfabeto es desconocido, intentamos interpretarlo hasta llegar a una hipótesis del significado de las letras bajo la cual se forman palabras comprensibles y periodos coherentes. Y entonces no queda ninguna duda de la corrección del desciframiento; porque no es posible que la armonía y la coherencia en las que esa intepretación pone todos los signos de aquel escrito fuera meramentae casual, ni que, dando otros valores totalmente distintos a los signos, se pudieran igualmente obtener palabras y periodos en esa combinación. De manera semejante, el desciframiento del mundo ha de acreditarse plenamente por sí mismo. Tiene que arrojar una luz análoga sobre todos los fenómenos del mundo y dar coherencia hasta a los más heterogéneos, de modo que se resuleva la contradicción incluso entre los que más contrastan ${ }^{27}$.

Por consiguiente, aquí Schopenahuer no plantea el problema de la fundamentación de la voluntad, sino la eficacia de su teoría con fines hermenéuticos. Entonces nosostros podemos considerar experimentalmente la teoría de la voluntad, es decir, la metafísica de Schopenahuer, como una hipótesis; otros son libres de interpretarla como categoria oculta, como intuición poética, como metáfora o en otros sentidos. En el caso de Schopenahuer, sin embargo, la hipótesis funciona. Funciona como principio unficador y criterio de interpretación de la experiencia en su conjunto y como "penetración de la esencia de las cosas que se agita bajo todos los fenómenos", para usar las palabras de Rohde. Es el gran golpe genial de Schopenhauer. Eso le permite -contra el parecer de Nietzsche que la considera fracasada-aquella Erklärung der Welt-explicación o desciframiento del mundo en que consiste, según él, la tarea de la filosofía. ¿Qué es lo que lo prueba? Simplemente el estupor con que nostros, leyendo a Schopenhauer, vemos resolver bajo

${ }^{26}$ En el seminario sobre las relaciones entre Nietzsche y Schopenhauer que se celebró en la Universidad de Nápoles el 4 de mayo del 2000 y después publicado en la revista Annuario filosofico.

${ }^{27}$ Schopenhauer, A., op. cit., vol. II, cap. 17, pp. 204 ss. 
nuestros ojos, como por un milagro, un enigma tras otro. Página tras página el autor nos lleva de la mano, con un estilo límpido y sobre la base de una sólida cultura clásica y científica, a la solución de tantos problemas y misterios de la vida, que uno no habría jamás esperado poder penetrar un día. ¿Qué otra cosa es sino filosofía? Esta 'lectura' del mundo, entendido precisamente como aquel documento escrito en una lengua desconocida, no la había proporcionado antes que Schopenhauer ningún filósofo; es por lo tanto de mucho valor, a pesar de que deje la ' $\mathrm{x}$ ' de la volutnad como ' $\mathrm{x}$ ', tras la cual se pueden poner en realidad otras infinitas ' $x$ '.

\section{No La COSA EN Sí, SINO EL UnO}

Es una hipótesis que consiente además de eliminar la división entre fénomeno y la cosa en sí, entre el mundo físico y el mundo metafísico, de mantener esto en aquello, de hacer del segundo la continuación del primero, en la medida en que no se puede captar, en suma nos lleva a concebir la realidad como única, la única que conocemos, pero que nuestro conocimiento nunca podrá abarcar en su inmensidad y profundidad. Es lo que Goethe antes incluso que Schopenhauer afirmó en el importante coloquio filosófico que mantuvo con Riemer, preceptor del hijo y bibliotecario en Weimar, el 2 (6/7) agosto de 1807: "Toda la filosofía de la naturaleza no es, a fin de cuentas, más que antropomorfismo, dicho de otra manera, el hombre, unidad en sí mismo, extiende esta idea de unidad a todo lo que no es él mismo, lo atrae en la propia unidad y lo unifica consigo mismo. Para conocer la naturaleza sería preciso que él fuese la naturaleza misma. Lo que enuncia de la naturaleza es algo real, existente, pero en relación con él. Pero lo que él dice de ella no es todo, no es la naturaleza entera, no la expresa en su totalidad [...] Esto para entendernos y ponernos de acuerdo con pensadores que hablan todavía de cosas en sí [...] Nosotros tendríamos que hablar no de cosas en sí, sino más bien del Uno en sí. Las cosas existen sólo en el modo de concebir de los hombres, que pone la diversidad y la pluralidad. Todo no es más que uno, ¿pero quién osaría hablar de este Uno en sí?"28.

¿Qué diferencia hay entre estas ideas y las de Nietzsche, para quien conocer es "esquematizar un caos a tenor de las necesidades prácticas»? No hay una diferencia de fondo, sino únicamente la caracterización del conocimiento, aquí de la ciencia en particular, como 'necesidades prácticas', y la de la naturaleza como 'caos'.

${ }^{28}$ Goethes Gespräche. Biedermannsche Ausgabe, ed. W. Herwig, vol. II, München, 1998, pp. 246 ss. 
En nuestra visión y conocimiento nunca podremos liberarnos del antropomorfismo, dado que, como hemos visto, esto equivaldría a liberarnos de nostros mismos. Todo aquello que es del hombre es humano y no puedo no serlo. Y se convierte en 'antropomórfico' en cuanto que el conocimeinto humano, como decía ya Spinoza, refleja más al hombre que a la cosa conocida $^{29}$. Pero este antropomorfismo periférico, necesario e inevitable no hay que confundirlo con aquellos antropomorfismos internos, que son fruto de la ignorancia y de errores, y a los que la mente humana está sujeta, pero que puede corregir o evitar, como por ejemplo la concepción ptolemáica de la tierra. En este sentido se da siempre con el antropomorfismo la fuerza que lo combate, y ciencia y filosofía consisten sobre todo en esta lucha.

\section{IO. LA DIFERENCIA Y LA PSICOLOGÍA}

Entre Nietzsche y Schopenhauer se mantiene una importante diferencia. Nietzsche hace de los dos mundos -fenómeno y noúmeno- un solo mundo, pero en el sentido del escepticismo y de la negación ${ }^{30}$. En Schopenahuer, al contrario, la unificación se da en el sentido de la afirmación. En el primer caso el orden humano histórico, tradicional, se disuelve, se pierde; en el segundo se conserva, se salva. La doctrina positiva de Schopenhauer conserva el mundo humano y su articulación en teoría y en la práctica y en las varias particiones de una y otra, con ramificaciones y genéros, especie y subespecie. Se pueden discutir las teorías particulares, cuestionar por ejemplo que el fundmaento de la moral sea, como él sostiene, la compasión y que ésta constituya una quiebra del principium individuationis, al contario que el egoismo entendido en sentido ordinario; o que la música exprese directamente la voluntad del mismo modo que el mundo como fenómeno. Pero el orden y la jerarquía de los valores se confirman: conocimiento, verdad, realidad y moralidad son circunscritos, pero son mantenidos; el valor de la bondad se salva, y prevalece sobre el genio como la luz del sol sobre la luz artificial. Más en genreal, los

${ }^{29}$ «...las ideas que tenemos de los cuerpos externos indican más la constitución de nuestro cuerpo que la naturaleza de los cuerpos externos», Etica, Torino: Boringhieri, 1959/1978, p. 89. «Conocer más o menos perfectamente un objeto no quiere decir tener en sí una imagen subjetiva que reproduzca el objeto, sino tener en sí el objeto mismo en su realidad ideal. Es el objeto mismo el que en nostros afirma o niega algo de sí mismo (Tr. br., II, 16, 5). En ese sentido hay que comprender la afirmación del Tractatus brevis (II, 15-16), que todo conocer es un padecer: en cuanto que es un acoger en sí una realidad ideal activa y viviente» Martinetti, Piero, Spinoza, Napoli: Bibliopolis, 1987, p. 150 ss.

${ }^{30}$ Ver por ejemplo FW $\$ 354$. 
valores del carácter (de la 'voluntad') prevalecen sobre los valores del intelecto. También la mística y los fenómenos paranormales encuentran en el sistema su lugar y su justificación.

Por le contrario, el escepticismo de Nietzsche, que es en primer lugar de naturaleza psicológica, si se usa moralísticamente (aplicado a una época y a un lugar) funciona bien; si se usa filosóficamente (sistemáticamente y en universal) se desvía y se corrompe. A partir de la Instauratio magna de Humano, demasiado humano y durante el resto de su vida, Nietzsche ha ejercido su genio psicológico para descubrir qué había detrás de los pensamientos, las creencias, las afirmaciones y las pretensiones de carácter espiritul. Y ha encontrado que eran necesidades egoistas, mejor dicho, fisiológicas. De este modo, ha pretendido que «la psicología se reconozca nuevamentae como señor de las ciencias, para servir y preparar a la cual existen las otras. Ya que la psicología es ya de nuevo la via que lleva a los problemas fundamentales» ${ }^{31}$. Consecuentemente, ha ampliado poco a poco su investigasción psicológica a las categorias sociales, pueblos, sociedad y, finalmente, a toda la humanidad. El nihilismo no es otra cosa que el descubrimiento del antropomorfismo y de la autoconservación que se anidan también detrás de toda conciencia superior, como detrás de la moralidad impulsada hasta los idelaes ascéticos ${ }^{32}$. $\mathrm{Y}$ esto porque cada viviente, ya se trate de un mosquito, de un hombre, delicuente o santo, o de toda la humanidad, no puede hacer otra cosa que considerarse el centro del universo y de depostiar en el universo caótico su unidad y racionalidad, y, más que el espinozano conatus sum esse servandi, su conatus potentiae querendae.

Por consiguiente, Nietzsche ha llegado a su máxima conquista filosófica, el nihilismo, sin 'detenerse mucho tiempo en el problema y sin preocuparse de él con amplias concatenaciones conceptuales', sino más bien psicologizando, después de todos los otros individuos particulares y colectivos, a aquel individuo supremo que es la humanidad, la especie. Y por su obra merece ser llmado el nuevo Maquiavelo. Pero el susodicho impulso que era dictado en él por la intolerancia de toda falsedad-motor y clave para comprender todas sus manifestaciones- y que le llevaba a luchar contra cualquier clase de tentativa, pero en particular la de aquellos avispados abogados del interés en sentido superior que son para él los filósofos sistemáticos -tentativas de edulcorar las asperezas de la existencia, de echar por encima mantos de espiritualidad mentirosa, con efectos de corrupción y de denigración

${ }^{31} \mathrm{JGB} \$ 23$ al final.

${ }^{32}$ Ver nota 3. 
de la vida y del mundo reales, pero siempre sacando las consecuencias de este alimento y goce- todo ello le llevaba a traducir, a transvalorar sistemáticamente los valores espiritulaes en valores fisiológicos ${ }^{33}$. Pero esto precisamentae, desarrollado sistemáticamente, hace precipitar todas las divisiones y distinciones de valores en el embudo único de la vitalidad, el llamado nihilismo activo, y hace comprender toda la dramáticidad de la reacción de su amigo Paul Deussen, al enterarse de que quien le había iniciado en Schopenhauer se había distanciado entonces de él: «¿Pero qué sucede? - ¿Ya no estás del lado de Schopenhauer? [...] es inconcebible, no es posible. - En este punto digo: ¡Nietzsche debe volver atrás!”34.

Nietzsche no volvió atrás. No podía. Habiendo suprimido el conocimiento, la libertad, la igualdad, la responsabilidad, la moralidad, la verdad y la misma realidad, entendida como una constitución cualquier de las cosas ${ }^{35}$, procedió siempre más hacia la 'naturalización del hombre'. El texto homo-natura era precisamente su ideal, concebido como ideal de veracidad, de pureza y de realismo. Y el desafío, sobre todo a sí mimso, del poeta Nietzsche, del gran poeta trágico Nietzsche, a amar la vida en su áspera autenticidad, de la que no sólo es terrible su carácter diabólico, como él dice, sino también la belleza. Es el amor fati. Pero es al mismo tiempo la legitimación de la ferocidad que pronto caracterizará la fase final de la crisis autodestructiva de la bimilenaria civilización cristiano-europea, el ocaso de Occidente.

traducción de Luis Enrique de Santiago Guervós

Universidad de Málaga

${ }^{33}$ KGW VIII 14[104].

${ }^{34}$ Janz, C. P., op. cit., vol. I, 1980, p. 733.

${ }^{35}$ KGW VIII 9[35]2, Presupuestos de esta hipótesis, otoño 1887. 
